biological law ceases to be tenable; but since man has the power of altering his environment and of adapting racial characters through conscious selection, it also follows that progress will not of necessity be followed by decadence; rather that, by aiming at a high mark, by deepening our knowledge of ourselves and of our world, and by controlling our energy and guiding our efforts in the light of that knowledge, we may prolong and hasten our ascent to ages and to heights as yet beyond prophetic vision.

\title{
International Catalogue of Scientific Literature.
}

$\mathrm{A} \mathrm{N}$ international conference of delegates from A scientific academies to consider the future of the International Catalogue of Scientific Literature was held last week by invitation of the Royal Society of London. Sir J. J. Thomson, president of the Royal Society, took the chair. The conference was attended by delegates from Denmark (Prof. Martin Knudsen), France (Prof. A. Lacroix), Holland (Prof. G. van Rijnberk), India (Sir H. H. Hayden and Dr. S. W. Kemp), Japan (Prof. H. Nagaoka), New Zealand (Prof. A. Dendy), Norway (Dr. Rolf Laache), Queensland (Sir Edw. Parrott), South Africa (Sir T. Muir), Sweden (Baron Alströmer), Switzerland (Dr. H. Escher, Dr. Marcel Godet, and Dr. H. H. Field), United States of America (Prof. L. E. Dickson, Mr. L. C. Gunnell, Dr. S. I. Franz, and Dr. Robert M. Yerkes), Victoria (Prof. E. W. Skeats), and Western Australia (Mr. G. B. Rushton). The Royal Society was represented by three of its officers (Sir J. J. Thomson, Sir David Prain, and Mr. J. H. Jeans), together with Prof. Henry E. Armstrong, Dr. F. A. Bather, Dr. P. Chalmers Mitchell, and Sir Arthur Schuster. The Italian delegates, having been delayed in the railway journey, were unfortunately not in time to take part in the proceedings.

The conference was called to consider whether any modifications in the present Catalogue are advisable and how the difficulties created by the war can best be overcome. It is well known that the Royal Society, in its "Catalogue of Scientific Papers," has undertaken to make an index of all books and papers on scientific subjects published during the nineteenth century. Sixteen quarto volumes of this important catalogue have already appeared. Four more volumes will probably be sufficient to complete the Author Catalogue for the period I800-Igoo. A corresponding Subject Catalogue is also being published.

In view of the ever-increasing number of scientific publications, the Royal Society realised that it could not continue to index the scientific literature of the whole world, but that such an undertaking should be carried out by a division of labour, each country indexing its own literature, the several catalogues so prepared being sent to a central bureau in London, where they should be combined and published in annual volumes. The "International Catalogue of Scientific Literature" was the outcome. It undertook to index scientific literature published after January I, I90I.

More than thirty countries joined in the scheme, each agreeing to index its own scientific literature upon cards which should be sent to London for incorporation in the printed volumes. Fourteen annual issues, each of seventeen volumes, have now been published indexing the scientific literature of I90I-I4. It was found that the sales and subscriptions to the volumes very nearly covered the cost of production.

It might have been predicted that a work of this kind, requiring harmony between workers of so many nationalities, could not be carried out without international jealousy and friction. Such has not proved to be the case. The greatest goodwill has existed between the various regional bureaux in the different countries and the central bureau in London.

The outbreak of war interrupted the work by restricting intercourse between the nations. The No. 2658 , VOL. IO6] finances of the catalogue have also suffered from the loss of subscriptions from Austria, Germany, Hungary, and Russia. At the same time the cost of printing and publishing has more than doubled. It was in these circumstances that the Royal Society convened last week's conference.

The delegates, while agreeing that it is essential that scientific literature should be fully indexed in order that the results of researches in every country might be made known quickly to all, entered into a full discussion as to how this indexing should be done, and passed in review the different agencies now engaged in such work.

They came to the conclusion that, even though a change be made in the future in the method of indexing, it is imperative to continue the International Catalogue of Scientific Literature in its present form until the literature published up to the end of the year I9I5, and possibly also that up to the end of the present year 1920, has been catalogued. In this way the important scientific work carried out during the war period will become available for reference at an early date and continuity in the work of indexing be maintained. This recommendation of the conference will come before the council of the Royal Society at their October meeting, and we are confident that the council will wish to give effect to the proposal if sufficient funds can be obtained.

A considerable sum of money will be required. It is estimated that the rise in salaries, wages, paper, and everything connected with printing and publishing is so great that an annual issue of the International Catalogue will now cost about 17,000 . In addition to the annual expenses, working capital of consider. able amount will be required. The sum mentioned at the conference was, we believe, $34,000 l$., this being the cost of two annual issues.

There is here an opportunity for someone to make a generous donation in aid of science. The Royal Society cannot be expected to provide the large sums now required out of its own resources. The society has already spent much money in the preparation of the Catalogue of Scientific Papers, and has lent $7500 l$. to the International Catalogue and made a further donation of r rool. from its funds. Contributions from European countries are invited, but mav prove difficult to obtain owing to the adverse rates of exchange. It would be a great misfortune if a work of this importance came to an end through lack of funds. We have here a league of nations engaged in making the results of scientific inquiry widely known; every effort should be made to help this league to live through what is evidently the critical period of its existence.

The question as to the future of the Catalogue after the completion of the twentieth issue was referred to a committee of the delegates for further consideration. Amongst other questions this committee will examine how far the work of the International Catalogue can be brought into relation with the many existing agencies for the publication of abstracts of scientific papers.

In addition to the abstracts prepared by manv of the scientific societies and to those published in periodical collections dealing with special subjects, there are card catalogues such as that under the 
charge of Dr. H. H. Field, of Zurich. It was suggested at the conference that these should be taken into account in fixing the form which the International Catalogue should take in the future.

The immediate problem, then, is to secure the indexing of the scientific literature published during the war. While this is being done, arrangements can be made for the efficient continuation of the work of cataloguing the scientific literature of the world.

\section{The International Congress of Mathematicians.}

THIS congress was opened at Strasbourg University on September 22 by the Rector, M. S. Clarety. The officers of the congress were then elected as follows :-Honorary President: M. Camille Jordan. President: M. Emile Picard. Vice-Presidents: Prof. Leonard Dickson, Sir Joseph Larmor, Prof. Nörlund, M. de la Vallée-Poussin, M. H. Villat, and M. Volterra. Secretary: M. Koenigs.

The delegates numbered 188 and represented 26 nations, amongst which may be mentioned Argentina (4), Australia (I), Brazil (I), Canada (I), Czecho-Slovakia (12), India (2), Japan (2), the Philippine Islands (I), Poland (4), Russia (I), and Serbia (2). The expenses of the congress, including the publishing of the proceedings, have been completely provided for. Of the sum required, 78,000 francs was contributed by public bodies, by industrial and commercial concerns, and by private persons. An interesting fact is that the French Government made its contribution of ro,ooo francs through the Ministry of Foreign Affairs, thereby recognising, it would appear, that such a congress has a certain significance in international politics. The subscriptions of delegates produced a further sum of 12,000 francs.

On Thursday, September 23, a general lecture was given by Sir Joseph Larmor on "Questions in Physical Indetermination." Sir Joseph said that of the three physical deductions upon which the validity of Einstein's theory depended, the two which had been verified by experiment, namely, the motion of the perihelion of Mercury and the deflection of light-rays by the sun, could be made to result equally well from a theory involving an æther. But the third Einstein prediction, the displacement of solar spectral lines, was inconsistent with any æether theory. In his opinion, it would be found, when conclusive observations had been made, that the third prediction was not verified. The doctrine that the universe is completely "full" originated with Descartes. The same doctrine was held by Newton, Huygens, Faraday, Fresnel, and Maxwell, but as a much more precise conception. The vortex theory and the elastic solid æther theory had had their day, but there was no reason at present why we should not admit the existence of an æthera new æther the properties of which were so different from those of ordinary matter that they could be expressed only in terms of non-Euclidean space. The alternative was complete abstraction, the absence of a basis on which to found our theories. The essence of Newtonian space, as enunciated in the works of Lie and Helmholtz, was the possibility of the existence of rigid bodies in motion. Newtonian space was the space of mechanics, for which $d x^{2}+d y^{2}+d z^{2}$ was invariant.

For Faraday and Maxwell, on the other hand, radiation was fundamental. The characteristic of Maxwellian space was complete transmission. A pulse travelled without change of form and without leaving anything behind-a principle that was in accord with experiments in light. This was the space of Minkowski, for which the corresponding invariant expression was $d x^{2}+d y^{2}+d z^{2}-c^{2} d t^{2}$.

As with Sir Joseph Larmor, so with most of the other contributors to the subject of relativity, the endeavour was directed towards the elimination of those paradoxes which the human mind finds it No. 2658 , VOL. IO6] difficult to accept rather than towards the further development of the theory itself. Thus M. Guillaume, setting forth from the remark that in the theory of relativity we were dealing with the apparent positions of bodies and that the difficulties of the theory arose from the fact that their "real" positions were supposed unknown, offered an alternative analysis in which the initial "real" positions of bodies were supposed known. He obtained results in which some of the paradoxes disappeared. M. Guillaume stated, however, that he had been in correspondence with Prof. Einstein, and had not been able to bring about a reconciliation of the two points of view.

The second general lecture, on "Relations between the Theory of Numbers and other Branches of Mathematics," was delivered on Friday, September 24, by Prof. Leonard Dickson, of Chicago. Prof. Dickson showed how the problem of obtaining rational solutions of certain classes of homogeneous equations was connected with the known properties of certain surfaces and with the theory of hypercomplex numbers.

In a lecture on the teaching of mathematical physics M. Volterra said that what might be called " analytical physics" now constituted an integral whole. Newton had reduced the problem of the universe to a problem in ballistics, and upon this basis Lagrange had founded his analytical mechanics. In a similar way the constitution of matter was for the modern physicist a problem in electricity, and we awaited a new Lagrange. At the present time there were two distinct methods of teaching mathematical physics in universities. The first might be called the mono. graphical method. The student followed in succession separate courses in hydrodynamics, optics, and so on. The weakness of this method was that there was no grasp of the subject as a whole. In the other method the student started with a course of mathematical analysis, and, so equipped, he proceeded to the various branches. The fault here was that in the first part of the course he was working without seeing his objective; he did not understand the purpose of his work or see its special difficulties. The course that M. Volterra advocated consisted of three parts. The first, on more or less historical lines, carried the student as far as the general equations. The second part was a discussion of those equations, including a classification of them according to their characteristics and a classification of the problems according to the methods of solution. The third part was the solution and discussion of specific problems. This scheme left for separate treatment those portions of analytical physics which depended upon the calculus of probability, as well as thermodynamics and some minor branches.

M. de la Vallee-Poussin in his lecture, "Sur les fonctions à variation bornée et les questions qui s'y rattachent," dealt with the fundamental theory of integration in the light of Baire's classification of functions. A11 classes of functions (Baire) are integrable in the sense of Lebesgue. Stieltjes's integral

$$
\int_{a}^{b} f(x) d a(x)
$$

can be defined by the process of Lebesgue, and it exists for all Baire functions $f$. The functional $\mathrm{U}(f)$ (Fréchet and Volterra), which has an assigned 